\title{
Clarification of the Etiology of Glomerella Leaf Spot and Bitter Rot of Apple Caused by Colletotrichum spp. Based on Morphology and Genetic, Molecular, and Pathogenicity Tests
}

\author{
Eugenia González, Turner B. Sutton, and James C. Correll
}

First and second authors: Department of Plant Pathology, North Carolina State University, Raleigh 27695; and third author: Department of Plant Pathology, University of Arkansas, Fayetteville 72701. Accepted for publication 4 April 2006.

\begin{abstract}
González, E., Sutton, T. B., and Correll, J. C. 2006. Clarification of the etiology of Glomerella leaf spot and bitter rot of apple caused by Colletotrichum spp. based on morphology and genetic, molecular, and pathogenicity tests. Phytopathology 96:982-992.

Morphological characteristics and vegetative compatibility groups (VCGs) of 486 isolates of Glomerella cingulata, Colletotrichum gloeosporioides, and C. acutatum collected from apple leaves with Glomerella leaf spot (GLS) symptoms and fruit with bitter rot symptoms in the United States and Brazil were studied. From this collection, 155 isolates of $G$. cingulata (93 from fruit, 61 from leaves, and 1 from buds), 42 isolates of $C$. gloeosporioides from fruit, and 14 isolates of $C$. acutatum (10 from fruit and 4 from leaves) were studied using mitochondrial (mt)DNA restriction fragment length polymorphism (RFLP) haplotypes. A subset of 24 isolates was studied by examining the sequence of a 200-bp intron of the glyceraldehyde 3-phosphate dehydrogenase (GDPH) nuclear gene. In addition, 98 isolates were tested for pathogenicity on leaves of cvs. Gala and Golden Delicious in the greenhouse, and 24 isolates were tested for pathogenicity on fruit of cv. Gala in growth chambers. In total, 238 and 225 isolates of $G$. cingulata were separated into

tively. Seven different mtDNA RFLP haplotypes were observed within isolates of G. cingulata, two within isolates of $C$. gloeosporioides, and two within isolates of $C$. acutatum. Phylogenetic trees, inferred based on maximum likelihood and maximum parsimony methods using the intron sequence, produced similar topologies. Each species was separated into distinct groups. All isolates tested were pathogenic on fruit, though only isolates with specific VCGs and haplotypes were pathogenic to leaves. Vegetative compatibility was a better tool than molecular characters for distinguishing isolates of $G$. cingulata pathogenic on both leaves and fruit from the ones pathogenic only on fruit. Isolates of $G$. cingulata capable of causing both GLS and bitter rot were included in haplotypes and groups based on the sequence analysis of the 200-bp intron that also included isolates capable of causing bitter rot only. Additionally, isolates of G. cingulata from the United States and Brazil which cause GLS were included in different haplotypes and sequence analysis groups. Therefore, one hypothesis is that isolates of G. cingulata from the United States capable of causing both GLS on foliage and bitter rot on fruit may have arisen independently of Brazilian isolates of $G$. cingulata capable of causing both GLS and bitter rot, and the two groups of isolates may represent distinct populations.
\end{abstract} four distinct morphological types and six VCGs, respectively. Five morphological types and six VCGs were identified among 74 and 36 isolates of $C$. gloeosporioides, respectively. Three morphological types and four VCGs were identified among 74 and 23 isolates of $C$. acutatum, respec-
Additional keywords: chromogenic types, nit mutants, perithecial types, self-fertile.
Bitter rot is a common fruit disease of apple in most countries where they are commercially grown. In temperate growing regions with high rainfall, it is considered one of the most important diseases and it can cause crop losses as great as $50 \%$ (26). Three taxa, Colletotrichum gloeosporioides (Penz.) Penz. \& Sacc., C. acutatum J. H. Simmonds, and Glomerella cingulata (Stoneman) Spauld. \& H. Schrenk, are associated with the bitter rot disease of apple (26). Monoconidial homothallic isolates of C. gloeosporioides from rotten fruit which readily produce fertile perithecia typically are designated $G$. cingulata (24), and often are referred to as perithecial isolates (25). In contrast, isolates which do not form fertile perithecia in culture typically are designated $C$. gloeosporioides (24).

The diversity of these pathogens on apple fruit was first recognized by Struble and Keitt (25), who described seven different types of $G$. cingulata based on colony color, distribution of perithecia in culture, and relative abundance of conidia. Isolates of C. gloeosporioides were characterized as conidial and chromogenic

Corresponding author: T. B. Sutton; E-mail address: turner_sutton@ @ ncsu.edu

DOI: 10.1094/PHYTO-96-0982

(C) 2006 The American Phytopathological Society (now recognized as $C$. acutatum) types. Isolates of $G$. cingulata (perithecial-type isolates) were differentiated from the conidial and chromogenic types by their ability to produce perithecia readily in culture. Plus and minus types, previously described by Edgerton (11), were observed among perithecial types and characterized based on colony color, distribution of perithecia, and relative abundance of conidia. The self-fertility of plus-type isolates was the main characteristic that distinguished these isolates from the minus-type isolates. Later, in 1952, Wheeler and McGahen (32) proposed new designations for the plus and minus perithecial types of $G$. cingulata based on distribution of perithecia and called them clumped-perithecial (CP) and scatteredperithecial (SP) types, respectively. More recent studies have shown considerable genetic and molecular variability within isolates of $C$. gloeosporioides and $G$. cingulata obtained from fruit with bitter rot symptoms $(3,25)$ and within populations of C. gloeosporioides and $G$. cingulata from other crops $(9,12$, 19,28,31).

In 1988, Leite et al. (21) described a new apple leaf spot disease on cvs. Gala and Golden Delicious in Paraná State in Brazil and demonstrated that it was caused by $G$. cingulata (perithecial isolates of $C$. gloeosporioides). This was the first report of any Colletotrichum sp. causing a leaf spot on apple in the orchard. 
The disease, named Glomerella leaf spot (GLS), has increased in severity and has become a major concern to Brazilian apple producers because the most widely grown cultivar, Gala, is highly susceptible to the disease. Under favorable conditions, GLS can result in $75 \%$ defoliation by harvest, weakening trees and reducing yield $(5,21,27)$. Additionally, GLS has been observed on other cultivars of commercial importance grown in Brazil, such as Granny Smith and Pink Lady (R. M. Sanhueza, personal communication). GLS first was reported in the United States in 1998 as a severe leaf spot on cv. Gala apples in two orchards in eastern Tennessee (14) and has been reported subsequently from Georgia and North Carolina. Experiments conducted in Georgia in the late 1960s (29) with an isolate of G. cingulata, however, suggest that strains of the fungus capable of causing a leaf spot were present much earlier. Although both GLS and bitter rot have been considered to be caused by the same pathogen, differences in morphology, cultural characteristics, and pathogenicity between isolates of the pathogen obtained from fruit or leaves have been observed $(21,29)$ and the strain or strains associated with GLS have not been identified conclusively and characterized, or compared with the widespread and endemic isolates of $G$. cingulata, C. gloeosporioides, and C. acutatum which cause bitter rot fruit symptoms on apple.

Although morphological and cultural characters are useful phenotypes for comparing strains of Colletotrichum at both the species and subspecies level, they are of limited utility in unambiguously identifying genotypes of the pathogen $(4,19)$. In contrast, both vegetative compatibility analysis $(9,13,22,30)$ and molecular techniques have been very helpful in delineating subspecific variation $(1,4,12,16,19,20,27,29,31)$. Using vegetative compatibility grouping, isolates of $C$. gloeosporioides obtained from different apple orchards in New Zealand were separated into six different vegetative compatibility groups (VCGs) (3). Guerber et al. (17), using mitochondrial (mt)DNA restriction fragment length polymorphisms (RFLPs), distinguished five haplotypes among isolates of $C$. acutatum, two haplotypes among isolates of C. gloeosporioides, and four haplotypes among isolates of G. cingulata obtained from apple fruit collected in different locations. Additionally, they sequenced a $1-\mathrm{kb}$ intron of the glutamine synthetase (GS) gene and a 200-bp intron of the glyceraldehyde 3-phosphate dehydrogenase (GDPH) nuclear gene that both are found in 10 species of Colletotrichum, including C. gloeosporioides, $C$. acutatum, and $G$. cingulata. The study indicated that isolates from apple fruit within the same species clustered, suggesting that sequence analysis of these two introns can provide a high level of resolution for determining inter- and intraspecific diversity and phylogenetic relationships among species of Colletotrichum.

Knowledge of the identity of the strain or strains of G. cingulata that cause GLS and their relationship to other strains of G. cingulata and taxa causing bitter rot on apples may provide clues to their origin and how to control the disease. Many practices that are used to manage bitter rot of apple fruit may not be effective for managing GLS. For example, in Brazil, fungicide programs developed to control bitter rot do not satisfactorily control GLS and fungicide sprays need to be applied after each $50 \mathrm{~mm}$ of rain to satisfactorily control GLS. This results in almost twice as many fungicide applications a year as needed to control bitter rot alone (R. M. Sanhueza, personal communication).

GLS continues to emerge as an important disease of apple in the United States as well as Brazil, and the genetic relationship among the more common isolates which cause bitter rot of apple fruit and isolates which can cause GLS remains unclear. The objectives of this study were to clarify the etiology of GLS and identify the genetic relationship among strains of $G$. cingulata associated with GLS and other strains or taxa associated with bitter rot of apple using morphological, genetic, and molecular techniques.

\section{MATERIALS AND METHODS}

Collection of monosporic isolates. In all, 486 isolates from symptomatic apple fruit and leaves from orchards in the United States and Brazil were examined (Table 1). The collection consisted of 97 isolates from leaves and 337 isolates from fruit from 10 orchards in five states (North Carolina, Alabama, Georgia, Tennesee, and Ohio) in the United States. Leaf isolates were obtained from four different cv. Gala orchards where GLS has been observed, including two orchards in eastern Tennessee (TN 1 and TN 2) where the disease was reported for the first time in the United States, one in Georgia (GA), and one in North Carolina (NC 1). In addition, 38 isolates were recovered from GSL lesions on apple leaves provided by R. M. Sanhueza from six different orchards of cv. Gala located in Rio Grande do Sul and Santa Catarina States, Brazil. Fourteen monosporic cultures from a collection of isolates of Dr. Sanhueza at the Empresa Brasileira de Pesquisa Agropecuaria (EMBRAPA) Uva e Vinho, Bento Gonçalves, RS, Brazil also were examined in this study (Table 1).

The collection included 339, 74, and 73 isolates identified as G. cingulata, C. gloeosporioides, and C. acutatum, respectively. Although $G$. cingulata isolates from apple produced the $C$. gloeosporioides anamorph, monoconidial isolates readily produced fertile perithecia, whereas isolates designated C. gloeosporioides do not and clearly represent genetically distinct isolates $(7,24)$.

Isolations and monosporic isolates. Fruit and leaf samples obtained in the field were stored for 1 to 7 days at $4{ }^{\circ} \mathrm{C}$ until they were processed. Fruit and leaves selected for the isolations were disinfested with $70 \%$ ethanol and $0.525 \% \mathrm{NaOCl}$, respectively, for $30 \mathrm{~s}$ and allowed to dry in a laminar hood. Each fruit and leaf isolate was obtained from a small piece of tissue cut from an arbitrarily selected lesion on a fruit or leaf. Fruit samples were plated on potato dextrose agar (PDA) and leaf samples on PDA amended with streptomycin $(200 \mu \mathrm{g} / \mathrm{ml})$. Dishes were incubated at $25^{\circ} \mathrm{C}$ with constant light for 7 to 20 days. To obtain monosporic isolates, perithecia or conidia of each isolate were placed in a drop of sterile deionized water on a microscope slide. Perithecia were covered with a cover slip, crushed to release the ascospores, and washed with a few drops of sterile deionized water into a petri dish containing water agar (WA). Conidia were washed directly from slides into the WA dishes. WA dishes containing crushed perithecia or conidia were incubated at $25^{\circ} \mathrm{C}$ with constant light for 10 to $15 \mathrm{~h}$ until the spores germinated. Single germinated spores were transferred to another petri dish containing WA. Fungal colonies emerging from isolates growing on WA were hyphal-tip transferred onto dishes of PDA. Monosporic isolates were stored desiccated on filter paper at $5^{\circ} \mathrm{C}$ as described previously (7).

Pathogenicity tests. In all, 87 isolates of $G$. cingulata (42 from fruit and 45 from leaves), 6 fruit isolates of $C$. gloeosporioides, and 5 isolates of $C$. acutatum (4 from fruit and 1 from leaves) (Table 2) were selected arbitrarily from the collection of isolates to conduct leaf pathogenicity tests on apple trees of cv. Gala. The pathogenicity of 12 isolates of $G$. cingulata ( 7 from fruit and 5 from leaves and pathogenic on leaves of Gala), 6 isolates of C. gloeosporioides from fruit, and 6 isolates of C. acutatum (3 from fruit and 3 from leaves) also were tested on trees of cv. Golden Delicious. Trees used for inoculations were maintained in the greenhouse and were cut back to two buds approximately 4 weeks before inoculations in order to generate one to two new shoots with 14 to 40 leaves each. Each tree was maintained for $24 \mathrm{~h}$ in individual humidity chambers at ambient temperature (approximately $24^{\circ} \mathrm{C}$ ) before inoculation. The humidity chambers consisted of plastic bags that covered the entire plant and also prevented cross contamination among trees during and after inoculation. After the preconditioning period, trees were removed from the humidity chambers and sprayed until runoff with spore suspensions $\left(1 \times 10^{5}\right.$ spores $\left./ \mathrm{ml}\right)$ of 7 - to 14 -day-old isolates. One 
tree was inoculated with each of the isolates selected for this experiment. After inoculation, trees were returned to the humidity chambers for $48 \mathrm{~h}$ at ambient temperature. Disease incidence was determined by calculating the percentage of affected leaves on each tree.

In all, 24 isolates of $G$. cingulata (13 from fruit and 11 from leaves), 5 fruit isolates of $C$. gloeosporioides, and 5 isolates of C. acutatum ( 3 from fruit and 2 from leaves) were selected to conduct fruit pathogenicity tests on apple fruit of cv. Gala. Pathogenicity was tested following a previously described procedure with some modifications (2). Briefly, squares of $2.5-b y-2.5-\mathrm{cm}$ laboratory towels were soaked with $0.3 \mathrm{ml}$ of a spore suspension $\left(1 \times 10^{5}\right.$ spores $\left./ \mathrm{ml}\right)$ and then placed on an uninjured surface of the fruit and covered with parafilm. Three fruit were inoculated with each isolate and were kept in humidity chambers at $26^{\circ} \mathrm{C}$ until completion of the experiment. Disease incidence was determined 7 to 10 days after inoculation and every 2 days for 6 days thereafter.

Morphological characterization. Morphological characterization of the 486 isolates growing on PDA was conducted with 8- to 15-day-old cultures based on colony color, conidial shape, the ability to produce perithecia in culture, and the distribution of conidial masses and perithecia within the colonies.

Vegetative compatibility tests. Nitrate nonutilizing (nit) mutants and testers were generated for each of the monosporic isolates in the collection $(n=486)$ as described previously $(8,23)$. Nit mutants were recovered from the entire collection of isolates. For isolates of $G$. cingulata and C. gloeosporioides, the minimal medium to generate nit mutants was amended with 1.5 to $3.0 \%$ potassium chlorate, and for isolates of $C$. acutatum with 4.5 to $6.0 \%$ potassium chlorate. One nit mutant per isolate was selected and stored desiccated on filter paper at $5^{\circ} \mathrm{C}$ for use in the comple- mentation tests. Sixteen pairs of complementing nit mutant testers were identified among the isolates. Each pair of testers was selected from 40 to 70 nit mutants from the same isolate. One of the nit mutants that complemented with at least three other nit mutants was used as one of the testers. Isolates of each pair of testers were obtained as described above and then stored desiccated on filter paper at $5^{\circ} \mathrm{C}$. Testers were paired in all possible combinations to verify that each pair represented a different VCG. Vegetative compatibility of all nit mutants generated was determined by pairing them on minimal medium with at least one of the testers. The formation of dense aerial wild-type mycelium where the nit mutants came in contact with each other indicated that the isolates were vegetatively compatible and belonged to the same VCG.

Molecular characterization. In all, 153 isolates of $G$. cingulata (92 from fruit and 61 from leaves), 42 fruit isolates of C. gloeosporioides, and 14 isolates of C. acutatum (10 from fruit and 4 from leaves) were examined for mtDNA RFLPs. Two isolates of C. acutatum (A38 and A138), two isolates of C. gloeosporioides ( $\mathrm{NC131}$ and $\mathrm{NC} 329$ ), and four isolates of $G$. cingulata (960, A45, NC211, and NC246) obtained from an isolate collection at the University of Arkansas also were included. These latter isolates represented eight different mtDNA RFLP haplotypes, (C1, D1, B3, B2, A2, A1, A4, and A3), and were used as reference isolates for the analysis of mtDNA RFLPs.

Mycelium production and DNA extraction. Spore suspensions with conidia, ascospores, or both, obtained from 8- to 15-dayold cultures, were used to inoculate $150 \mathrm{ml}$ of potato dextrose broth (PDB) in 200-ml Erlenmeyer flasks. Cultures were incubated in a rotary shaker for 3 to 4 days at $26^{\circ} \mathrm{C}$ and $250 \mathrm{rpm}$. Mycelium was harvested by filtering the PDB through miracloth

TABLE 1. Isolates of Colletotrichum acutatum, C. gloeosporioides, and Glomerella cingulata obtained from leaf and fruit samples

\begin{tabular}{|c|c|c|c|c|}
\hline \multirow[b]{2}{*}{ Species $^{y}$} & \multirow[b]{2}{*}{ Geographical origin ${ }^{\mathrm{z}}$} & \multicolumn{2}{|c|}{ Source } & \multirow[b]{2}{*}{ Number of isolates } \\
\hline & & Host tissue & Cultivar & \\
\hline C. acutatum & Brazil 2 & Leaf & Gala & 2 \\
\hline C. acutatum & Brazil 2 & Fruit & Gala, Golden Delicious, Fuji & 4 \\
\hline C. acutatum & Brazil 4 & Leaf & Gala & 16 \\
\hline C. acutatum & Brazil 8 & Fruit & Gala, Golden Delicious, Fuji & 4 \\
\hline C. acutatum & NC 1 & Fruit & Gala & 1 \\
\hline C. acutatum & NC 2 & Fruit & Granny Smith & 46 \\
\hline C. gloeosporioides & $\mathrm{AL}$ & Fruit & Golden Delicious & 11 \\
\hline C. gloeosporioides & $\mathrm{NC} 2$ & Fruit & Granny Smith & 21 \\
\hline C. gloeosporioides & NC 3 & Fruit & Golden Delicious, Delicious & 42 \\
\hline G. cingulata & Brazil 1 & Leaf & Gala & 7 \\
\hline G. cingulata & Brazil 2 & Leaf & Gala & 1 \\
\hline G. cingulata & Brazil 2 & Fruit & Gala & 1 \\
\hline G. cingulata & Brazil 2 & Bud & Gala & 1 \\
\hline G. cingulata & Brazil 3 & Leaf & Gala & 3 \\
\hline G. cingulata & Brazil 5 & Leaf & Gala & 3 \\
\hline G. cingulata & Brazil 6 & Leaf & Gala & 7 \\
\hline G. cingulata & Brazil 7 & Leaf & Gala & 2 \\
\hline G. cingulata & Brazil 8 & Leaf & Gala & 1 \\
\hline G. cingulata & GA & Leaf & Gala & 25 \\
\hline G. cingulata & GA & Fruit & Gala & 45 \\
\hline G. cingulata & NC 1 & Leaf & Gala & 60 \\
\hline G. cingulata & NC 1 & Fruit & Gala & 15 \\
\hline G. cingulata & $\mathrm{NC} 2$ & Fruit & Granny Smith & 82 \\
\hline G. cingulata & NC 3 & Fruit & Golden Delicious, Delicious & 19 \\
\hline G. cingulata & $\mathrm{NC} 4$ & Fruit & Granny Smith & 51 \\
\hline G. cingulata & NC 5 & Fruit & Gala & 1 \\
\hline G. cingulata & $\mathrm{OH}$ & Fruit & Molly's Delicious & 3 \\
\hline G. cingulata & TN 1 & Leaf & Gala & 4 \\
\hline G. cingulata & $\mathrm{TN} 2$ & Leaf & Gala & 8 \\
\hline
\end{tabular}

y Species designation was assigned after morphological characterization.

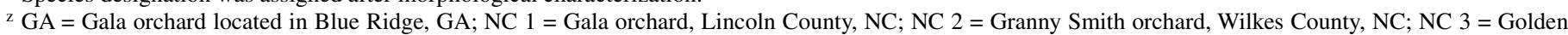
Delicious and Delicious orchard at the Central Crops Research Station Clayton, NC; NC 4 = Granny Smith orchard, Lincoln County, NC; NC 5 = Gala orchard located in Wilkes County, NC; OH = Molly's Delicious orchard, Ohio; Brazil 1, 4, 5, 6, 7, and $8=$ Gala and Golden Delicious orchards, Santa Catarina State, Brazil; Brazil 2 and 3 = Gala orchards, Rio Grande do Sul State, Brazil; TN 1 = Gala orchard, Cleveland, TN; TN $2=$ Gala orchard, Buffalo Valley, TN; AL = Golden Delicious orchard, Alabama; Brazil 1, 2, 3, 4, 5, 6, 7, and $8=$ isolates obtained from a collection of isolates maintained by Dr. Rosa Maria Sanhueza at the Empresa Brasileira de Pesquisa Agropecuaria (EMBRAPA) Uva and Vinho, Bento Gonçalves, RS, Brazil. 
(Calbiochem, La Jolla, CA), and stored at $-80^{\circ} \mathrm{C}$. Freeze-dried mycelium was ground with a pestle in a mortar containing liquid nitrogen. Total DNA was extracted by the DNA "mini-prep" procedure as described previously (6). Genomic DNA (1 $\mu \mathrm{g})$ was digested with the restriction enzyme MspI (Promega Corporation, Madison, WI). Restricted DNA was separated electrophoretically in $0.8 \%$ agarose gels and transferred to positively charged nylon membranes (GE Osmonics Inc, Minnetonka, MN). Southern blots were probed with two nonoverlapping mtDNA clones $(4 \mathrm{u} 40$ and $2 \mathrm{u} 18$ ) developed by Correll et al. (10) to determine mtDNA RFLP haplotypes. An enhanced chemiluminescence DNA labeling kit (ECL; Amersham, Arlington Heights, IL) was used to label the clones. Isolates with the same mtDNA restriction fragment pattern were placed in the same mtDNA RFLP haplotype.

Intron amplification and DNA sequencing. Primers GDF1 (5'-GCCGTCAACGACCCCTTCATTGA-'3) and GDR1 (5'-GGGTGGAGTCGTACTTGAGCATGT-'3) (22) were used to amplify the 200-bp intron of the GDPH nuclear gene from 14 isolates of G. cingulata (9 from fruit and 5 from leaves), 8 fruit isolates of C. gloeosporioides, and 2 isolates of $C$. acutatum (1 from fruit and 1 from leaves) selected from the isolates previously examined for mtDNA RFLPs and vegetative compatibility (Table 3). PCR amplification of the intron was performed in a P $x 2$ Thermal cycler (Thermo Hybaid, Franklin, MA) using the following protocol: 35 cycles of denaturation at $94^{\circ} \mathrm{C}$ for $1 \mathrm{~min}$, annealing at $60^{\circ} \mathrm{C}$ for $1 \mathrm{~min}$, and an extension at $72^{\circ} \mathrm{C}$ for $3 \mathrm{~min}$. Amplification of the intron was confirmed electrophoretically in a $2 \%$ agarose gel. PCR products were purified using the QIAquick PCR Purification Kit (Qiagen, Inc., Valencia, CA), and sequenced for both strands following the procedure previously described by Guerber et al. (17).

Sequence alignment and sequence analysis. Sequences were entered into the DNA sequence editor Chromas (version 1.45; School of Health Science, Griffith University, Queensland, Australia) and then aligned using The Biology WorkBench 3.2 (San Diego Supercomputer Center, University of California, San Diego). Sequence analysis and basic statistics were performed using PAUP 4.0 beta 10 as described by Guerber et al. (17). Two methods of phylogenetic tree inference were used: maximum likelihood (ML) and maximum parsimony (MP). Tree topologies were evaluated by statistical confidence based on values for bootstrap 50\% majority-rule consensus for 100 replicates.

\section{RESULTS}

Pathogenicity tests. All isolates tested were pathogenic on fruit (data not shown), producing typical bitter rot symptoms. Of the
87 isolates of $G$. cingulata recovered either from fruit or leaves, only isolates in VCGs 1, 4, and 5 collected from orchards of cv. Gala located in Georgia, North Carolina, Brazil, and Tennessee were capable of causing a leaf spot on Gala (Table 2). Only isolates of $G$. cingulata that were pathogenic to leaves of cv. Gala were capable of causing a leaf spot on trees of cv. Golden Delicious. All isolates of $G$. cingulata pathogenic on leaves were very aggressive, and disease incidence was approximately $100 \% 4$ days after inoculation (data not shown). None of the isolates of C. gloeosporioides or $C$. acutatum tested caused leaf spot symptoms.

Morphological characterization. Twelve morphological types were observed among the isolates of $G$. cingulata, $C$. gloeosporioides, and C. acutatum examined (Table 4). Isolates of G. cingulata and C. gloeosporioides produced cylindrical conidia with rounded ends and were differentiated by the ability of the self-fertile isolates to produce perithecia in culture. Isolates of G. cingulata were separated into four morphological types mainly distinguished by the distribution of perithecia in culture (Fig. 1). Although morphological characteristics of morphological type SP3 isolates were similar to those of SP1 isolates, perithecia produced by SP3 isolates were sterile. SP3 isolates never were recovered directly from fruit or leaves, but originated from segregation of $\mathrm{CP}$ monosporic isolates. All morphological types of G. cingulata produced dark-colored acervuli. Isolates of C. gloeosporioides were separated into five morphological types that differed mainly by the distribution of conidial masses in culture and colony color (Fig. 2). Three morphological types were found among isolates of $C$. acutatum (SSC, SSNC, and SSNC(O)). These morphological types differed in colony pigmentation (Fig. 3 ). All morphological types of $C$. acutatum produced fusiform conidia with pointed ends and none formed perithecia in culture. Conidia were produced mostly within the mycelium and some in orange masses scattered within the colonies.

Isolates of $G$. cingulata were recovered from all orchards, except the orchard in Alabama and an orchard in Brazil. Although morphological types SP1 and CP were widely distributed, SP2 and SP3 were identified in only one and two orchards, respectively. SP1 was the only morphological type observed from the collection in Brazil (Table 5).

C. gloeosporioides was less widespread and was recovered only from the orchard in Alabama and two orchards in North Carolina (NC2 and NC3). Four morphological types of C. gloeosporioides were found in the NC3 orchard, whereas the other two orchards had two types each (Table 5).

$\mathrm{SSNC}(\mathrm{O})$ isolates of $C$. acutatum were recovered from fruit and leaf samples from three orchards in Brazil (Brazil 2, 4, and 8)

TABLE 2. Pathogenicity of isolates of Glomerella cingulata, Colletotrichum gloeosporioides, and C. acutatum on leaves of cv. Gala

\begin{tabular}{|c|c|c|c|c|c|c|}
\hline \multirow[b]{2}{*}{ Isolate designation } & \multirow[b]{2}{*}{ Species } & \multirow[b]{2}{*}{ Geographic origin } & \multirow[b]{2}{*}{$\mathrm{VCG}^{\mathrm{y}}$} & \multicolumn{2}{|c|}{ Source } & \multirow[b]{2}{*}{ Pathogenicity $^{\mathrm{z}}$} \\
\hline & & & & Host tissue & Cultivar & \\
\hline BR $1,4,7,9,10,11,12,13,16,20,21$ & G. cingulata & Brazil & 4,5 & Leaf & Gala & + \\
\hline CROTTS(L) 2-6,8-10,13-19,22 & G. cingulata & North Carolina & 1 & Leaf & Gala & + \\
\hline GA(L) $1,2,4,5,7-12,14,16$ & G. cingulata & Georgia & 1 & Leaf & Gala & + \\
\hline GA $3,5-8,10,12,21,22,24$ & G. cingulata & Georgia & 1 & Fruit & Gala & + \\
\hline TN 7 & G. cingulata & Tennessee & 1 & Leaf & Gala & + \\
\hline CROTTS $1,3,5,6,8-13$ & G. cingulata & North Carolina & 2 & Fruit & Gala & - \\
\hline RD 1,3 & G. cingulata & North Carolina & 6 & Fruit & Delicious & - \\
\hline LD $3,5-8,10,12,13,15-17,23,25,30-32,41$ & G. cingulata & North Carolina & 2,6 & Fruit & Granny Smith & - \\
\hline $\mathrm{OH} 1-3$ & G. cingulata & Ohio & 3 & Fruit & Molly's Delicious & - \\
\hline TN $1,5,8,9,11$ & G. cingulata & Tennessee & $\mathrm{n} / \mathrm{a}$ & Leaf & Gala & - \\
\hline AL $1,4,5,9$ & C. gloeosporioides & Alabama & 8,7 & Fruit & Golden Delicious & - \\
\hline $\operatorname{LD~Cg~} 1,8$ & C. gloeosporioides & North Carolina & 9 & Fruit & Granny Smith & - \\
\hline $\mathrm{LD} \mathrm{Ca}(\mathrm{b}) 4,6$ & C. acutatum & North Carolina & $\mathrm{n} / \mathrm{a}$ & Fruit & Granny Smith & - \\
\hline LD Ca 5,10 & C. acutatum & North Carolina & $\mathrm{n} / \mathrm{a}$ & Fruit & Granny Smith & - \\
\hline $\mathrm{BR} \mathrm{Ca} 4$ & C. acutatum & Brazil & 13 & Leaf & Gala & - \\
\hline
\end{tabular}

y $\mathrm{VCG}=$ vegetative compatibility group; $\mathrm{n} / \mathrm{a}=$ not applicable.

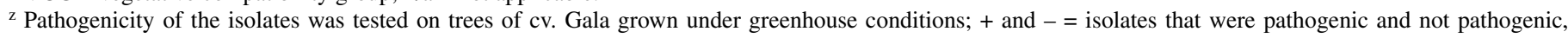
respectively. 
(Table 5). SSC and SSNC isolates were obtained only from fruit from two orchards in North Carolina.

VCGs and morphological types. Among the 486 isolates, 325 isolates of $G$. cingulata $(96.2 \%), 36$ isolates of $C$. gloeosporioides $(48.6 \%)$, and 23 isolates of $C$. acutatum $(31.1 \%)$ could be characterized based on vegetative compatibility (Table 6). Six VCGs were found within isolates of G. cingulata, whereas five VCGs were found within morphological type SP1. Isolates within VCG6 were either CP- or SP3-type cultures. Of the 325 isolates of
G. cingulata, 132 belonged to VCG-1, 75 to VCG-2, and 85 to VCG-6. Brazilian isolates of G. cingulata generally were placed in VCG-4 and VCG-5. Six VCGs were found among four morphological types of $C$. gloeosporioides. Isolates of C. acutatum separated into four VCGs. VCG-13 and VCG-14 isolates had the same morphological type, $\operatorname{SSNC}(\mathrm{O})$, and included 17 isolates from Brazil. Six isolates of $C$. acutatum obtained from Granny Smith fruit from one orchard (NC2) were separated into two VCGs (VCG-15 and VCG-16), and also were differentiated into

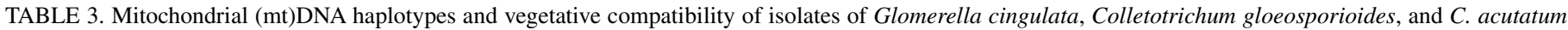
used for the sequence analysis of the 200-bp intron of the glyceraldehyde 3-phosphate dehydrogenase gene

\begin{tabular}{|c|c|c|c|c|c|c|}
\hline \multirow[b]{2}{*}{ Isolate designation } & \multirow[b]{2}{*}{ mtDNA haplotypes } & \multirow[b]{2}{*}{$\mathrm{VCG}^{\mathrm{z}}$} & \multirow[b]{2}{*}{ Species } & \multirow[b]{2}{*}{ Geographical origin } & \multicolumn{2}{|c|}{ Source } \\
\hline & & & & & Host tissue & Cultivar \\
\hline $\mathrm{GA}(\mathrm{L}) 1$ & G1 & 1 & G. cingulata & Georgia & Leaf & Gala \\
\hline LD 10 & G1 & 2 & G. cingulata & North Carolina & Fruit & Granny Smith \\
\hline $\mathrm{OH} 1$ & G1 & 3 & G. cingulata & Ohio & Fruit & Molly's Delicious \\
\hline GA 17 & G1.1 & 1 & G. cingulata & Georgia & Fruit & Gala \\
\hline LD 17 & G1.1 & 2 & G. cingulata & North Carolina & Fruit & Granny Smith \\
\hline CROTTS 13 & $\mathrm{G} 2$ & 2 & G. cingulata & North Carolina & Fruit & Gala \\
\hline CROTTS 8 & $\mathrm{G} 2$ & 2 & G. cingulata & North Carolina & Fruit & Gala \\
\hline BR 8 & G3 & 4 & G. cingulata & Brazil & Leaf & Gala \\
\hline BR 17 & G3 & 5 & G. cingulata & Brazil & Leaf & Gala \\
\hline BR 21 & G4 & 5 & G. cingulata & Brazil & Leaf & Gala \\
\hline LD 5 & A3 & 6 & G. cingulata & North Carolina & Fruit & Granny Smith \\
\hline TN 9 & A3 & $?$ & G. cingulata & Tennessee & Leaf & Gala \\
\hline LD 5 & A3 & 6 & G. cingulata & North Carolina & Fruit & Granny Smith \\
\hline LD 1 & A3.1 & 6 & G. cingulata & North Carolina & Fruit & Granny Smith \\
\hline AL 7 & B2 & 7 & C. gloeosporioides & Alabama & Fruit & Golden Delicious \\
\hline LD 54 & B2 & 10 & C. gloeosporioides & North Carolina & Fruit & Granny Smith \\
\hline GD 8 & $\mathrm{~B} 2$ & 11 & C. gloeosporioides & North Carolina & Fruit & Golden Delicious \\
\hline RD 16 & $\mathrm{~B} 2$ & 12 & C. gloeosporioides & North Carolina & Fruit & Red Delicious \\
\hline GD 13 & B2 & 17 & C. gloeosporioides & North Carolina & Fruit & Golden Delicious \\
\hline $\mathrm{AL} 1$ & B3 & 8 & C. gloeosporioides & Alabama & Fruit & Golden Delicious \\
\hline LD Cg 12 & B3 & 9 & C. gloeosporioides & North Carolina & Fruit & Granny Smith \\
\hline $\mathrm{RD} 7$ & B3 & 18 & C. gloeosporioides & North Carolina & Fruit & Red Delicious \\
\hline LD Ca 21 & $\mathrm{C} 1$ & 15 & C. acutatum & North Carolina & Fruit & Granny Smith \\
\hline BR Ca 17 & D1 & 14 & C. acutatum & Brazil & Leaf & Gala \\
\hline
\end{tabular}

z VCG = vegetative compatibility group.

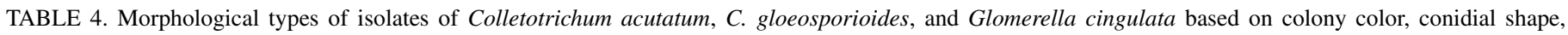
ability to produce perithecia in culture, and distribution of acervuli and perithecia in culture ${ }^{\mathrm{x}}$

\begin{tabular}{|c|c|c|c|c|c|c|c|}
\hline \multirow[b]{2}{*}{ Species } & \multicolumn{3}{|c|}{ Perithecia ${ }^{y}$} & \multirow[b]{2}{*}{ Distribution } & \multirow[b]{2}{*}{$a / p^{\mathrm{z}}$} & \multirow[b]{2}{*}{ Colony } & \multirow[b]{2}{*}{ Conidial shape } \\
\hline & Type & Fertility & Color & & & & \\
\hline$\overline{G . \text { cingulata }}$ & SP1 & Self-fertile & $\cdots$ & $\begin{array}{l}\text { Single or small groups } \\
\text { over entire colony }\end{array}$ & $a / p$ & $\begin{array}{l}\text { Dark gray, sparse and } \\
\text { appressed mycelium }\end{array}$ & $\begin{array}{l}\text { Cylindrical with } \\
\text { rounded ends }\end{array}$ \\
\hline G. cingulata & $\mathrm{SP} 2$ & Self-fertile & $\ldots$ & Scattered small groups & $a / p$ & Gray and appressed mycelium & $\begin{array}{l}\text { Cylindrical with } \\
\text { rounded ends }\end{array}$ \\
\hline G. cingulata & SP3 & Sterile & $\ldots$ & $\begin{array}{l}\text { Single or small groups } \\
\text { over entire colony }\end{array}$ & $a / p$ & $\begin{array}{c}\text { Dark gray, sparse and } \\
\text { appressed mycelium }\end{array}$ & $\begin{array}{l}\text { Cylindrical with } \\
\text { rounded ends }\end{array}$ \\
\hline G. cingulata & $\mathrm{CP}$ & Self-fertile & $\ldots$ & Scattered clumps & $a / p$ & $\begin{array}{l}\text { Gray/white and abundant } \\
\text { mycelium }\end{array}$ & $\begin{array}{l}\text { Cylindrical with } \\
\text { rounded ends }\end{array}$ \\
\hline C. gloeosporioides & SS1 & $\ldots$ & Light & $\begin{array}{l}\text { Small orange masses over } \\
\text { entire colony }\end{array}$ & $a$ & $\begin{array}{l}\text { Light gray and appressed } \\
\text { mycelium }\end{array}$ & $\begin{array}{l}\text { Cylindrical with } \\
\text { rounded ends }\end{array}$ \\
\hline C. gloeosporioides & $\mathrm{SS} 2$ & $\ldots$ & Dark & $\begin{array}{l}\text { Small orange masses over } \\
\text { entire colony }\end{array}$ & $a$ & $\begin{array}{l}\text { Light gray and abundant } \\
\text { mycelium }\end{array}$ & $\begin{array}{l}\text { Cylindrical with } \\
\text { rounded ends }\end{array}$ \\
\hline C. gloeosporioides & $\mathrm{SS} 3$ & $\ldots$ & Dark & $\begin{array}{l}\text { Large orange scattered } \\
\text { masses }\end{array}$ & $a$ & $\begin{array}{l}\text { Light gray and abundant } \\
\text { mycelium }\end{array}$ & $\begin{array}{l}\text { Cylindrical with } \\
\text { rounded ends }\end{array}$ \\
\hline C. gloeosporioides & SS4 & $\ldots$ & Dark & $\begin{array}{l}\text { Small orange masses over } \\
\text { entire colony }\end{array}$ & $a$ & $\begin{array}{l}\text { Dark gray and abundant } \\
\text { mycelium }\end{array}$ & $\begin{array}{l}\text { Cylindrical with } \\
\text { rounded ends }\end{array}$ \\
\hline C. gloeosporioides & SS5 & $\cdots$ & Dark & $\begin{array}{l}\text { Large orange scattered } \\
\text { masses }\end{array}$ & $a$ & $\begin{array}{l}\text { Dark gray and abundant } \\
\text { mycelium }\end{array}$ & $\begin{array}{l}\text { Cylindrical with } \\
\text { rounded ends }\end{array}$ \\
\hline C. acutatum & $\mathrm{SSNC}(\mathrm{O})$ & $\ldots$ & $\mathrm{n} / \mathrm{a}$ & Mostly within mycelium & $a$ & $\begin{array}{l}\text { Light orange, no pigment in } \\
\text { culture }\end{array}$ & $\begin{array}{l}\text { Fusiform with } \\
\text { pointed ends }\end{array}$ \\
\hline C. acutatum & $\mathrm{SSC}$ & $\ldots$ & $\mathrm{n} / \mathrm{a}$ & Mostly within mycelium & $a$ & Red pigment in culture & $\begin{array}{l}\text { Fusiform with } \\
\text { pointed ends }\end{array}$ \\
\hline C. acutatum & SSNC & $\ldots$ & $\mathrm{n} / \mathrm{a}$ & Mostly within mycelium & $a$ & $\begin{array}{l}\text { Gray-olive, no pigment in } \\
\text { culture }\end{array}$ & $\begin{array}{l}\text { Fusiform with } \\
\text { pointed ends }\end{array}$ \\
\hline
\end{tabular}

${ }^{x}$ Isolates, 8 to 15 days old and grown on potato dextrose agar medium, were characterized after incubation at $25^{\circ} \mathrm{C}$ with constant light.

y Type $=$ morphological type, Color $=$ acervulus color, and $\mathrm{n} / \mathrm{a}=$ isolates did not produce acervuli in culture.

$\mathrm{z}$ The presence of acervuli or perithecia in culture is indicated by $a$ or $p$, respectively. 
two morphological types, SSC and SSNC, respectively. Only isolates of $G$. cingulata that belonged to VCGs 1, 4, and 5 were pathogenic on leaves (Table 7).

In all, 102 isolates were not compatible with any of the VCGs. These isolates included 3 SP1 (Brazil and Tennesee) and $10 \mathrm{CP}$ (Tennesee) isolates of $G$. cingulata; $3 \mathrm{SS} 1,10 \mathrm{SS} 3,8 \mathrm{SS} 4$, and 17 SS5 isolates of C. gloeosporioides, all from North Carolina; and $9 \mathrm{SSNC}(\mathrm{O})$ (Brazil), 21 SSC (North Carolina), and $21 \mathrm{SSNC}$ (North Carolina) isolates of C. acutatum.

mtDNA RFLPs. Eleven different mtDNA RFLP haplotypes were found among the isolates of $G$. cingulata, C. gloeosporioides, and $C$. acutatum examined (Fig. 4). The majority of the isolates of G. cingulata from the United States (77 of 86) belonged to haplotypes G1 and G2. The 21 isolates of $G$. cingulata from Brazil were placed into haplotypes G3 and G4. The 14 isolates of C. acutatum were represented by two haplotypes, whereas all 8 isolates of $C$. acutatum from the United States were characterized as haplotype $\mathrm{C} 1$. All six isolates from Brazil were D1 isolates.
Haplotypes G1, G1.1, G3, and G4 of G. cingulata were the only haplotypes that included isolates pathogenic to leaves. All isolates characterized as G3 and G4 haplotypes were from Brazil and were capable of causing a leaf spot, whereas G1 and G1.1 haplotypes (from the United States) also included isolates not pathogenic on leaves (Table 7).

Sequence analysis of the 200-bp intron. The 200-bp intron of the GDPH gene was amplified successfully from isolates of G. cingulata, C. gloeosporioides, and C. acutatum. Both phylogenetic analyses, ML, and MP inferred phylogenetic trees with the same topology and same statistically supported groups for the sequence of the intron of the isolates (Fig. 5). Only the phylogenetic tree inferred based on ML is included in the results because all bootstrap values in the statistical analysis for this tree were equal to 100 . Two main clusters were observed in the phylogenetic tree. One cluster included the G. cingulata/C. gloeosporioides complex and was divided into seven groups. The other cluster included only isolates of $C$. acutatum.

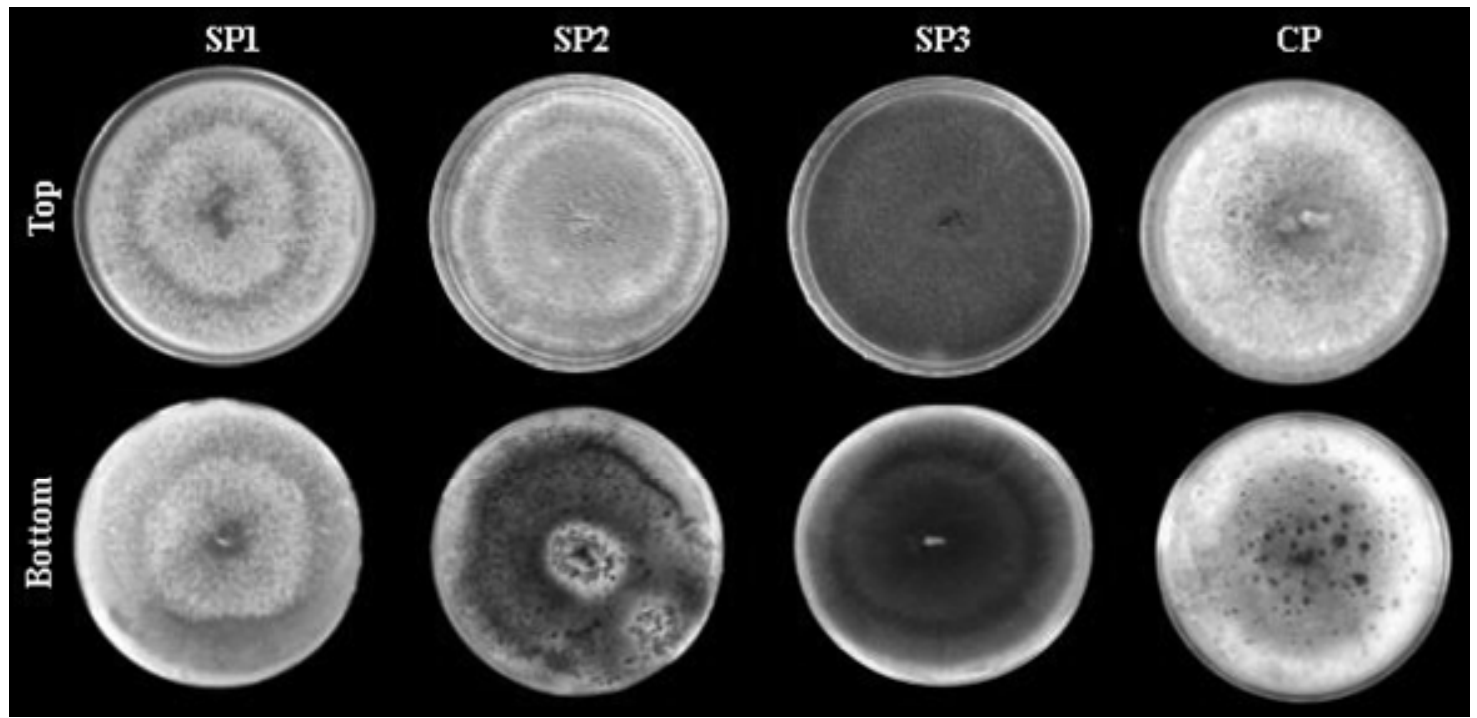

Fig. 1. Morphological types found among isolates of Glomerella cingulata obtained from symptomatic fruit and leaves collected in different orchards located in the United States and Brazil. Characterization was based on colony color, conidial shape, the ability to produce perithecia in culture, and the distribution of conidial masses and perithecia within the colonies.

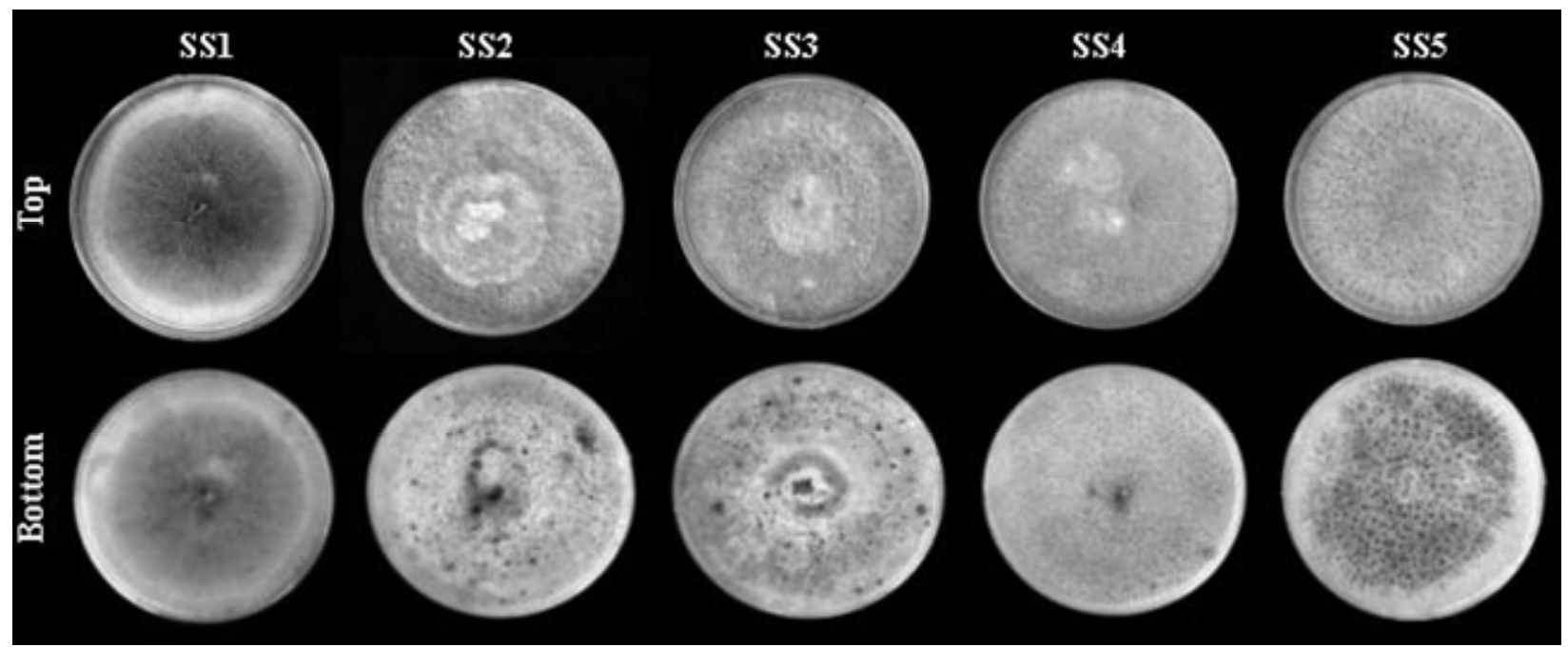

Fig. 2. Morphological types found among isolates of Colletotrichum gloeosporioides obtained from symptomatic fruit and leaves collected in different orchards located in the United States and Brazil. Characterization was based on colony color, conidial shape, the ability to produce perithecia in culture, and the distribution of conidial masses and perithecia within the colonies. 


\section{DISCUSSION}

In this study, we found that the component of the population of $G$. cingulata that can cause GLS is limited to specific genotypes. Isolates of $G$. cingulata capable of causing GLS belonged to morphological type SP1, VCGs 1, 4, and 5, and mtDNA haplotypes G1, G1.1, G3, and G4 and were obtained only from fruit or leaves of cv. Gala. Although isolates of C. acutatum from Brazil were recovered from leaves of Gala, they were not pathogenic to leaves and likely were growing saprophytically in necrotic tissue.
Morphological characterization, VCG analysis, and molecular characterization each provided a different degree of resolution for characterizing genetic diversity at both the taxonomic and population levels for isolates of C. gloeosporioides, C. acutatum, and $G$. cingulata from apple fruit and leaves. Morphological characters used in this study included colony color, conidial shape, and the ability to produce perithecia in culture that are traits commonly used to differentiate isolates of $G$. cingulata, C. gloeosporioides, and $C$. acutatum $(1,3,18,19,23)$. The ability of isolates of G. cingulata to produce perithecia in culture (self-fertility) sepa-

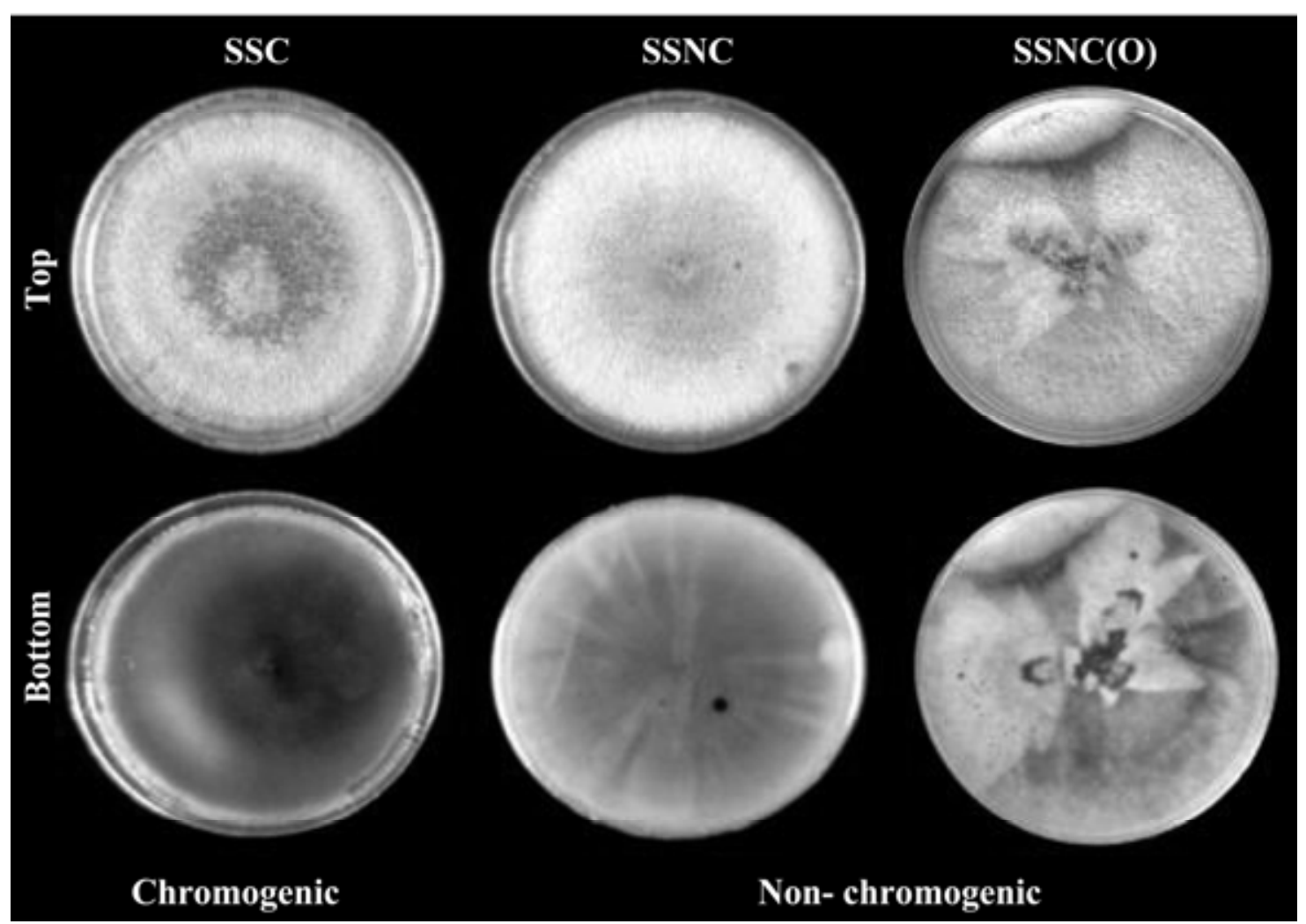

Fig. 3. Chromogenic and nonchromogenic morphological types found among isolates of Colletotrichum acutatum obtained from symptomatic fruit and leaves collected in different orchards located in the United States and Brazil. Characterization was based on colony color, conidial shape, the ability to produce perithecia in culture, and the distribution of conidial masses and perithecia within the colonies.

TABLE 5. Geographical origin of morphological types of isolates of Glomerella cingulata, Colletotrichum gloeosporioides, and C acutatum collected from orchards in the United States and Brazil

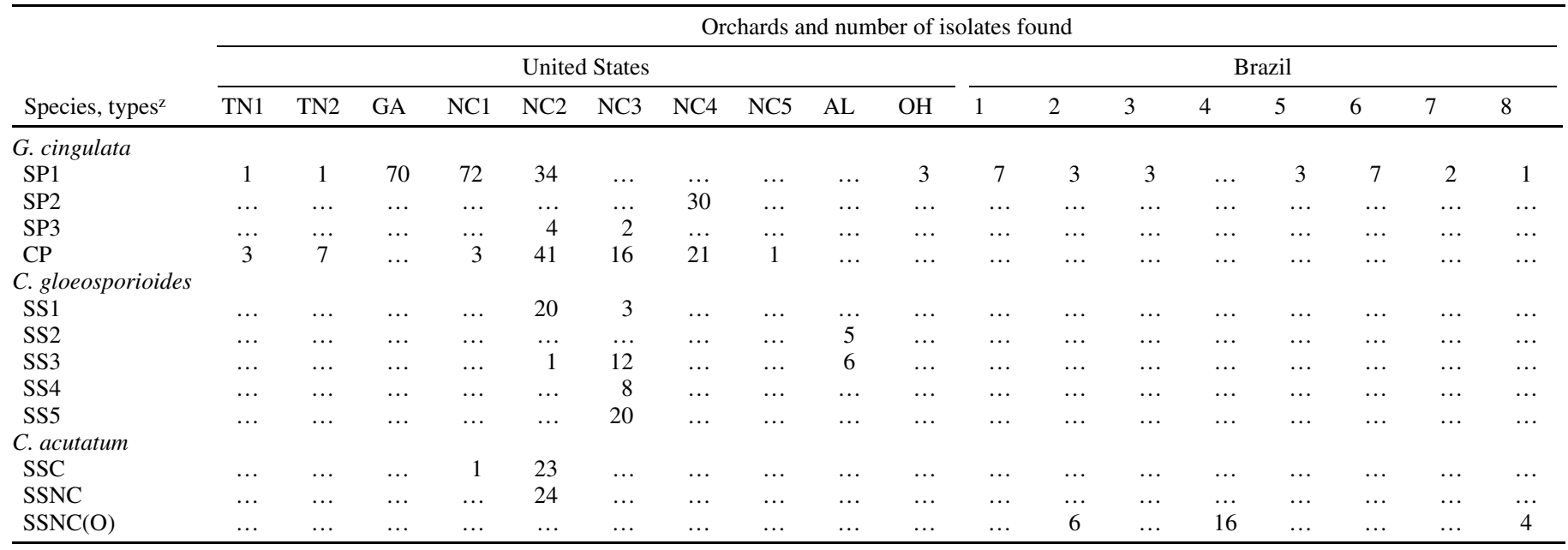

${ }^{\mathrm{z}}$ SP1 isolates found in Brazil orchards 2 and 8 were recovered from leaves of cv. Gala. SS1 isolates found in NC3 were recovered from fruit of cv. Delicious. $\mathrm{SSNC}(\mathrm{O})$ isolates found in Brazil 2 were recovered from leaves of cv. Gala and those found in Brazil 8 were recovered from fruit of cv. Fuji and Golden Delicious. 
rated them from isolates of C. gloeosporioides. Isolates of $C$. acutatum also lacked the ability to produce perithecia in culture. Shi et al. (24) observed similar morphological differences among isolates of Colletotrichum obtained from apple fruit with bitter rot symptoms. Colony color and the production of a red pigment in culture were useful for distinguishing $C$. acutatum from C. gloeosporioides and $G$. cingulata and separating isolates of $C$. acutatum from the United States and Brazil. Isolates from the United States produced a red pigment in culture or gray-olive colonies, whereas those from Brazil produced light-orange colonies. The chromogenic and nonchromogenic morphological types observed by others $(20,24)$ within isolates of $C$. acutatum from apple fruit with bitter rot symptoms coincide with our description of the morphological types of $C$. acutatum observed in the United States.

To distinguish additional morphological types among isolates of $G$. cingulata and $C$. gloeosporioides, it was necessary to characterize the distribution of acervuli and perithecia within the colonies. Struble and Keitt (25) distinguished two morphological types within isolates of $G$. cingulata from apple fruit with bitter rot symptoms that were differentiated mainly by colony color and the distribution of perithecia within the colony. The plus or $\mathrm{CP}$ type produced light colonies with perithecia in scattered clumped

TABLE 6. Vegetative compatibility group (VCG), morphological type, origin, and source of isolates of Colletotrichum acutatum, C. gloeosporioides, and Glomerella cingulata

\begin{tabular}{|c|c|c|c|c|c|}
\hline VCG & Morphological type & Species & No. of isolates ${ }^{y}$ & Host tissue & Geographical origin $^{z}$ \\
\hline 1 & SP1 & G. cingulata & $86(\mathrm{~L}), 46(\mathrm{~F})$ & Leaf, fruit & $\mathrm{NC}, \mathrm{GA}, \mathrm{TN}$ \\
\hline 2 & SP1, SP2 & G. cingulata & 45 (SP1), 30 (SP2) & Fruit & $\mathrm{NC}$ \\
\hline 3 & SP1 & G. cingulata & 3 & Fruit & $\mathrm{OH}$ \\
\hline 5 & SP1 & G. cingulata & 21 & Leaf & Brazil \\
\hline 6 & $\mathrm{CP}$ & G. cingulata & 85 & Fruit & $\mathrm{NC}$ \\
\hline 6 & SP3 & G. cingulata & 6 & Fruit & $\mathrm{NC}$ \\
\hline 7 & SS2 & C. gloeosporioides & 5 & Fruit & $\mathrm{AL}$ \\
\hline 10 & SS1 & C. gloeosporioides & 2 & Fruit & $\mathrm{NC}$ \\
\hline 11 & SS3 & C. gloeosporioides & 2 & Fruit & $\mathrm{NC}$ \\
\hline 12 & SS5 & C. gloeosporioides & 3 & Fruit & $\mathrm{NC}$ \\
\hline 13 & $\operatorname{SSNC}(\mathrm{O})$ & C. acutatum & 8 & Leaf & Brazil \\
\hline 14 & $\operatorname{SSNC}(\mathrm{O})$ & C. acutatum & $7(\mathrm{~L}), 2(\mathrm{~F})$ & Leaf, fruit & Brazil \\
\hline 15 & SSC & C. acutatum & 3 & Fruit & $\mathrm{NC}$ \\
\hline 16 & SSNC & C. acutatum & 3 & Fruit & $\mathrm{NC}$ \\
\hline
\end{tabular}

${ }^{x}$ Morphological types previously described in Table 5 based on colony color, conidial shape, the ability to produce perithecia in culture, and distribution of acervuli and perithecia in culture.

${ }^{\mathrm{y}} \mathrm{L}=$ isolates obtained from leaves and $\mathrm{F}=$ isolates obtained from fruit.

${ }^{\mathrm{z}} \mathrm{NC}=$ North Carolina, $\mathrm{GA}=$ Georgia, $\mathrm{TN}=$ Tennesee, $\mathrm{OH}=\mathrm{Ohio}$, and $\mathrm{AL}=$ Alabama, United States.

TABLE 7. Pathogenicity of the Glomerella cingulata/Colletotrichum gloeosporioides complex (Complex) and C. acutatum according to the groups obtained in the sequence analysis of the 200-bp intron of the glyceraldehyde 3-phosphate dehydrogenase gene, mitochondrial (mt)DNA haplotypes, and vegetative compatibility groups (VCGs)

\begin{tabular}{|c|c|c|c|c|c|c|c|}
\hline \multirow[b]{2}{*}{ Species, sequence analysis ${ }^{\mathrm{w}}$} & \multirow[b]{2}{*}{ mtDNA } & \multirow[b]{2}{*}{$\mathrm{VCG}^{\mathrm{x}}$} & \multirow[b]{2}{*}{ Origin ${ }^{y}$} & \multicolumn{2}{|l|}{ Source } & \multicolumn{2}{|c|}{ Pathogenicity ${ }^{z}$} \\
\hline & & & & Cultivar & Host tissue & Leaf & Fruit \\
\hline \multicolumn{8}{|l|}{ Complex } \\
\hline \multirow[t]{8}{*}{ Group 1 (G. cingulata) } & G1 & 1 & GA, NC, TN & Gala & Leaf & + & + \\
\hline & & 1 & $\mathrm{NC}$ & Gala & Fruit & + & + \\
\hline & & 2 & $\mathrm{NC}$ & Gala, Granny Smith & Fruit & - & + \\
\hline & & 3 & $\mathrm{OH}$ & Molly's Delicious & Fruit & - & + \\
\hline & G1.1 & 1 & $\mathrm{TN}$ & Gala & Fruit & + & + \\
\hline & & 2 & $\mathrm{NC}$ & Granny Smith & Fruit & - & + \\
\hline & & 2 & $\mathrm{NC}$ & Granny Smith & Fruit & - & + \\
\hline & $\mathrm{G} 2$ & 2 & $\mathrm{NC}$ & Gala, Granny Smith & Fruit & - & + \\
\hline \multirow[t]{3}{*}{ Group 2 (G. cingulata) } & G3 & 4 & Brazil & Gala & Leaf & + & + \\
\hline & & 5 & Brazil & Gala & Leaf & + & + \\
\hline & G4 & 5 & Brazil & Gala & Leaf & + & + \\
\hline \multirow[t]{2}{*}{ Group 3 (G. cingulata) } & A3 & 6 & $\mathrm{NC}, \mathrm{TN}$ & Granny Smith, Red and Golden Delicious, Gala & Fruit & - & + \\
\hline & A 3.1 & 6 & $\mathrm{NC}, \mathrm{TN}$ & Granny Smith, Gala & Fruit & - & + \\
\hline \multirow[t]{2}{*}{ Group 4 (C. gloeosporioides) } & B2 & 7 & $\mathrm{AL}$ & Golden Delicious & Fruit & - & + \\
\hline & & 12 & $\mathrm{NC}$ & Delicious & Fruit & - & + \\
\hline \multirow[t]{3}{*}{ Group 5 (C. gloeosporioides) } & B2 & $\mathrm{n} / \mathrm{a}$ & $\mathrm{NC}$ & Golden Delicious & Fruit & - & + \\
\hline & B3 & 8 & AL & Golden Delicious & Fruit & - & + \\
\hline & & 9 & $\mathrm{NC}$ & Granny Smith & Fruit & - & + \\
\hline \multirow[t]{2}{*}{ Group 6 (C. gloeosporioides) } & B2 & 11 & $\mathrm{NC}$ & Delicious & Fruit & - & + \\
\hline & B3 & 11 & $\mathrm{NC}$ & Delicious & Fruit & - & + \\
\hline Group 7 (C. gloeosporioides) & $\mathrm{B} 2$ & 10 & $\mathrm{NC}$ & Granny Smith & Fruit & - & + \\
\hline \multirow[t]{2}{*}{ C. acutatum } & $\mathrm{C} 1$ & 15 & $\mathrm{NC}$ & Granny Smith & Fruit & - & + \\
\hline & D1 & 14 & Brazil & Gala & Leaf & - & + \\
\hline
\end{tabular}

${ }^{\mathrm{w}}$ Groups based on maximum likelihood and maximum parsimony phylogenetic trees.

${ }^{x}$ Isolates that were not compatible with any of the VCGs are indicated by n/a.

y Geographic origin; GA = Georgia, NC = North Carolina, TN = Tennesee, $\mathrm{OH}=$ Ohio, and AL = Alabama, United States.

${ }^{z}$ Pathogenic and not pathogenic isolates indicated by + and - , respectively. 
masses, and the minus or SP type produced dark colonies and perithecia singly or in groups of two or three perithecia over the entire colony. Additionally, they observed that SP-type isolates did not occur among isolates recovered from naturally infected fruit, but were derived from monosporic isolations of CP-type isolates. The characteristics of the CP-type isolates that we observed agree with those of CP-type isolates observed by Struble and Keitt (25). Although morphological characteristics of the SPtype isolates described by Struble and Keitt (25) are similar to those described in the present study for SP1 and SP3-type isolates, SP3 isolates were not found in the orchard and resulted from segregation of CP isolates.

mtDNA haplotypes and groups based on intron sequence analysis included not only isolates of $G$. cingulata pathogenic to leaves and fruit but also isolates of $G$. cingulata pathogenic to fruit only. Isolates of $G$. cingulata from Brazil capable of causing both GLS and bitter rot belonged to haplotypes G3 and G4, whereas those from the United States were included in haplotypes G1 and G1.1. Haplotypes G3 and G4 included only isolates of $G$. cingulata capable of causing GLS and bitter rot; however, haplotypes G1 and G1.1 also included isolates of G. cingulata that were not pathogenic on leaves but were capable of causing bitter rot. However, the VCG analysis separated leaf isolates that were pathogenic and nonpathogenic within haplotypes G1 and G1.1 into VCG-1 and VCG-2, respectively. The sequence analysis of the intron clearly demarcated the $G$. cingulatalC. gloeosporioides complex from C. acutatum. Within the G. cingulatal C. gloeosporioides complex, seven clearly delineated groups were identified. Interestingly, there was no overlap in the groups repre-

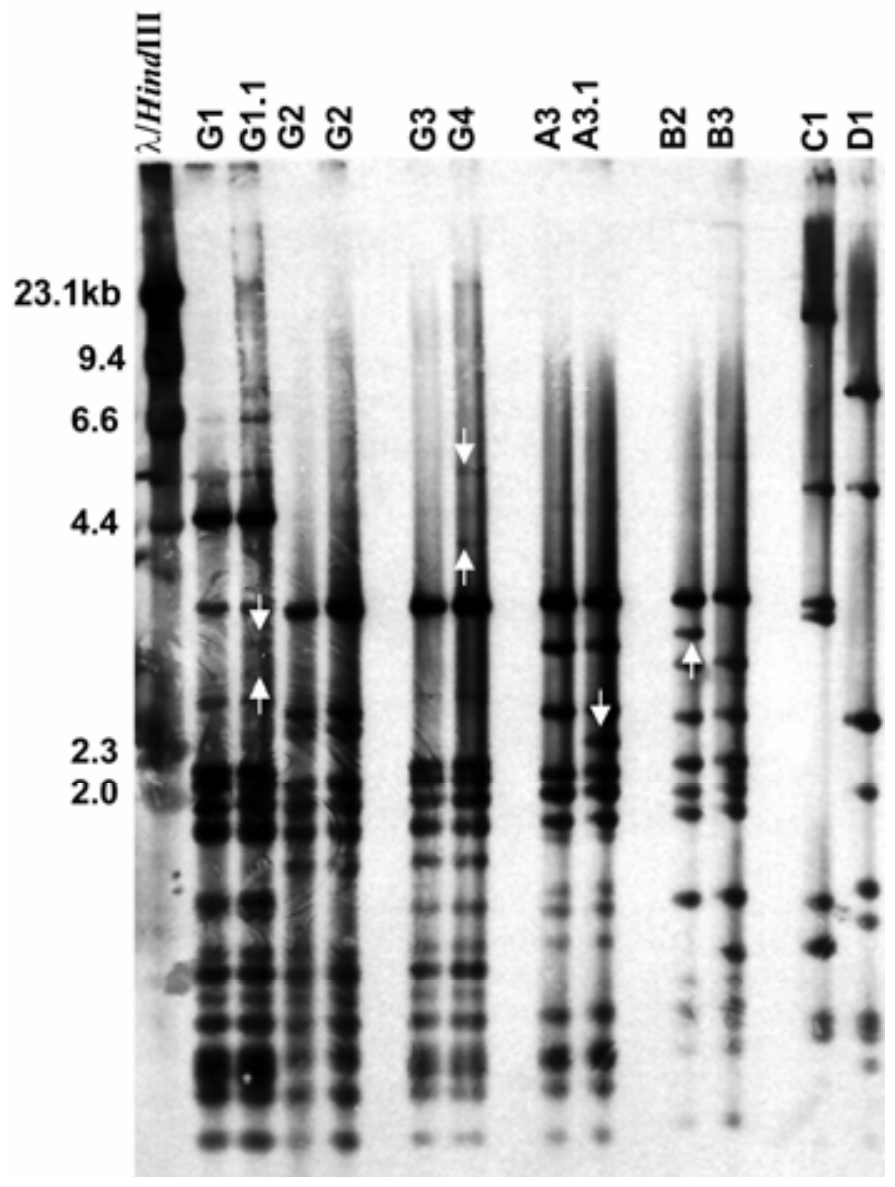

Fig. 4. Mitochondrial DNA restriction fragment length polymorphism haplotypes found among isolates of Glomerella cingulata (lanes 1 to 4, 6 and 7, 9 and 10), Colletotrichum gloeosporioides (lanes 12 and 13), and C. acutatum (lanes 15 and 16) collected from fruit and leaves of apple. White arrows show the bands that differentiated similar haplotypes. senting the teleomorphic isolates (G. cingulata) and the anamorphic isolates (C. gloeosporioides). Thus, it is possible that the two broader groups ( $G$. cingulata versus $C$. gloeosporioides) represent genetically isolated taxa. However, the intron sequence analysis also grouped isolates of $G$. cingulata capable of causing GLS and bitter rot together with isolates of $G$. cingulata capable of causing bitter rot only in the same group. Only isolates of $G$. cingulata with haplotypes A3 and A3.1 that were capable of causing bitter rot were distinguished in the mtDNA RFLP and sequence analysis of the GDPH gene intron from isolates of $G$. cingulata capable of causing both GLS and bitter rot. Therefore, only the VCG analysis distinguished isolates of $G$. cingulata capable of causing GLS and bitter rot from isolates of $G$. cingulata capable of causing bitter rot only. Other studies involving vegetative compatibility among isolates of $C$. orbiculare and C. coccodes, and pathogenicity tests, suggested a distinct correspondence between VCGs and pathogenic characteristics or virulence of phenotypes $(22,30)$. Similar correlations also were observed between VCGs and forma speciales of strains of Fusarium oxysporum obtained from different crops, suggesting that vegetative compatibility may represent a fast and easy way to distinguish pathotypes of the pathogen $(9,23)$.

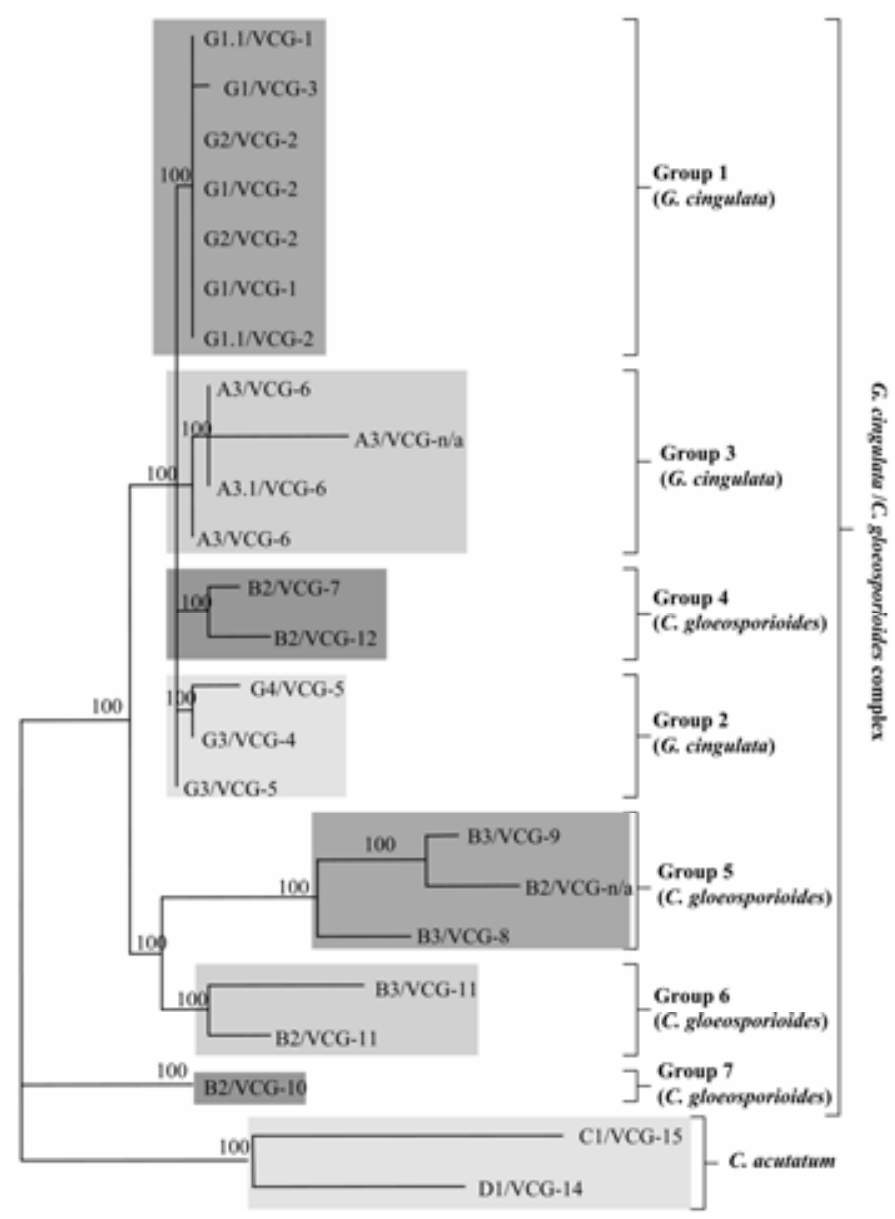

Fig. 5. Maximum likelihood phylogenetic tree based on the sequence of a 200-bp intron of the glyceraldehyde 3-phosphate dehydrogenase nuclear gene showing the relationship among and between isolates of Glomerella cingulata, Colletotrichum gloeosporioides, and C. acutatum obtained from a collection of isolates previously characterized based on morphology, vegetative compatibility, and mitochondrial (mt)DNA restriction fragment length polymorphisms. Values for bootstrap $50 \%$ majority-rule consensus are labeled on the branches of the tree. Number of bootstrap replicates was equal to 100 . Scale bar represents the number of transformations from one character to another. Isolates are designated by their mtDNA haplotype and vegetative compatibility group (VCG); $\mathrm{n} / \mathrm{a}=$ isolates were not compatible with any of the VCGs. 
mtDNA RFLP analysis also distinguished isolates of $G$. cingulata and $C$. acutatum from the United States from isolates of $G$. cingulata and $C$. acutatum from Brazil. Isolates of $G$. cingulata from the United States belonged to haplotypes G1, G1.1, G2, A3, and A3.1, whereas isolates of G. cingulata from Brazil belonged to haplotypes G3 and G4. Isolates of $C$. acutatum from the United States belonged to haplotype $\mathrm{C} 1$, and isolates of $C$. acutatum from Brazil were included into haplotype D1. Although, isolates of $G$. cingulata from the United States and Brazil were included in the same cluster ( $G$. cingulata/C. gloeosporioides complex) in the sequence analysis of the intron, they were separated in different groups within the cluster. Isolates from the United States were included in groups 1 and 3, and isolates from Brazil belonged to group 2. Isolates of $C$. acutatum from the United States and Brazil occurred in the same intron group.

All of the isolates from the United States that were tested that caused GLS belonged to a single VCG (VCG 1), a single intron group, and two similar mtDNA haplotypes. However, other isolates which caused only fruit infections apparently were genetically similar to GLS isolates in that, although they were not in VCG 1, they had the same or similar mtDNA haplotypes and belonged to the same intron group. All of the isolates from Brazil that were tested that caused GLS belonged to two VCGs (VCGs 4 and 5), two similar mtDNA haplotypes, and a second intron group. Considering the presence of GLS for over 15 years in Brazil, it was not surprising that isolates that cause GLS were observed in multiple VCGs. These results suggest that VCG-1, VCG-4, and VCG-5 probably represent clonal populations of $G$. cingulata that arose independently within the United States and Brazil.

The origin of the GLS fungus is not clear. All isolates of the various taxa can cause fruit infections, but only a limited number of genotypes can cause GLS; therefore, one hypothesis is that the genotypes that cause GLS may have originated from the more endemic fruit-infecting population, at least based on the U.S. samples. This hypothesis is supported by the fact that the fruitand leaf-infecting isolates belong to similar mtDNA haplotypes. Evidence at this time suggests that it may exist in the population in a low frequency and, if this hypothesis is correct, then cv. Gala probably acts as a selection force. In a companion study (15), we characterized 1,230 fruit isolates of the three taxa from two orchards of cv. Granny Smith. Only $17 \%$ of the isolates were the SP1 type and none of these were in VCG-1. However, of 1,170 fruit and leaf isolates tested from an orchard of Gala located approximately $3 \mathrm{~km}$ from one of the Granny Smith orchards, 94\% of the isolates were SP1 and all were in VCG-1. A necrotic leaf blotch strain of G. cingulata reported by Taylor in 1971 (29), pathogenic to leaves of Golden Delicious, also is evidence that isolates of $G$. cingulata capable of causing a leaf spot were present in the population of fungi causing bitter rot of apples in the United States, but did not become predominant until Gala became widely planted. The alternative hypothesis that the fruit-infecting isolates originated from the leaf-infecting component of the population also is plausible. However, GLS only recently has been observed and reported (14), whereas bitter rot has been endemic in many apple-growing areas of the United States for many years and was widely reported in the early horticultural literature. A third hypothesis is that the genotypes that cause GLS in the United States have recently been introduced. However, we consider this unlikely, because GLS isolates from the United States and Brazil fall into different VCG groups. The GLS fungus may have arisen from isolates of $G$. cingulata that originally were pathogenic only on fruit, because isolates of $G$. cingulata from the United States that were capable of causing both GLS and bitter rot were included in the same mtDNA haplotypes and intron groups that also included isolates of $G$. cingulata capable of causing bitter rot only. Sequence analysis of multiple genes from isolates of $G$. cingulata pathogenic to fruit and leaves and isolates of $G$. cingulata pathogenic to fruit only may help to clarify the origin of the GLS fungus.

Based on this study, management strategies for GLS on Gala should focus on maintaining isolates of $G$. cingulata capable of causing GLS at a low frequency in the population. Currently, the only way to accomplish this is to maintain a rigorous bitter rot control program from the time the orchard is established. This likely will entail more frequent sprays than needed on other cultivars and postharvest sprays to minimize late-season leaf infections. Additionally, leaves should be shredded with a flail mower each fall after leaf fall to minimize the carryover of inoculum.

\section{ACKNOWLEDGMENTS}

We thank R. M. Sanhueza, EMBRAPA Uva e Vinho, Bento Gonçalves, Brazil, for providing the Brazilian cultures and advice during the course of the study; A. Myers and O. Anas for technical assistance; G. Payne for allowing us to conduct the molecular characterization in his laboratory; and the owners of Miller's Orchard in Wilkes County, NC, and Knob Creek Orchard in Lincoln County, NC, for allowing us to work in their orchards.

\section{LITERATURE CITED}

1. Afanador-Kafuri, L., Minz, D., Maymon, M., and Freeman, S. 2003. Characterization of Colletotrichum isolates from tamarillo, passiflora, and mango in Colombia and identification of a unique species from the genus. Phytopathology 93:579-587.

2. Aráuz, L. F., and Sutton, T. B. 1989. Temperature and wetness duration requirements for apple infection by Botryosphaeria obtusa. Phytopathology 79:440-444.

3. Beever, R. E., Olsen, T. L., and Parkes, S. L. 1995. Vegetative compatibility groups in Colletotrichum gloeosporioides (Glomerella cingulata) from apple and other fruits. Aust. J. Plant Pathol. 24:126-132.

4. Buddie, A. G., Martínez-Culebras, P., Bridge, P. D., García, M. D., Querol, A., Cannon, P. F., and Monte, E. 1999. Molecular characterization of Colletotrichum strains derived from strawberry. Mycol. Res. 103:385394.

5. Cerezine, P. C., Leite, R. P., and Tsuneta, M. 1992. Efeito de tratamentos químicos no controle da mancha foliar de Glomerella en macieira, no estado de Paraná. Fitopatol. Brasil. 17:258-267.

6. Correll, J. C., Gordon, T. R., and McCain, A. H. 1992. Genetic diversity in California and Florida populations of the pitch canker fungus Fusarium subglutinans f. sp. pini. Phytopathology 82:415-420.

7. Correll, J. C., Guerber, J. C., Wasilwa, L. A., Sherill, J. F., and Morelock, T. E. 2000. Inter- and intra-species variation in Colletotrichum and mechanisms which affect population structure. Pages 145-179 in: Colletotrichum: Host Specificity, Pathology, and Host-Pathogen Interaction. D. Prusky, S. Freeman, and M. Dickman, eds. The American Phytopathological Society, St. Paul, MN.

8. Correll, J. C., Klittich, J. R., and Leslie, J. F. 1987. Nitrate nonutilizing mutants of Fusarium oxysporum and their use in vegetative compatibility tests. Phytopathology 77:1640-1646.

9. Correll, J. C., Puhalla, J. E., and Schneider, R. W. 1986. Identification of Fusarium oxysporum f. sp. apii on the basis of colony size, virulence, and vegetative compatibility. Phytopathology 73:396-400.

10. Correll, J. C., Rhoads, D. D., and Guerber, J. C. 1993. Examination of mitochondrial DNA restriction fragment length polymorphisms, DNA fingerprints, and randomly amplified polymorphic DNA of Colletotrichum orbiculare. Phytopathology 83:1199-1204.

11. Edgerton, C. W. 1914. Plus and minus strains in the genus Glomerella. Am. J. Bot. 1:244-254.

12. Freeman, S., Katan, T., and Shabi, E. 1996. Characterization of Colletotrichum gloeosporioides isolates from avocado and almond fruits with molecular and pathogenicity tests. Appl. Environ. Microbiol. 62:10141020.

13. Gichuru, E. K., Várzea, M. P., Rodrigues, C. J., Jr., and Masaba, D. M. 2000. Vegetative compatibility grouping of Colletotrichum kahawae in Kenya. J. Phytopathol. 148:233-237.

14. González, E., and Sutton, T. B. 1999. First report of Glomerella leaf spot (Glomerella cingulata) of apple in the United States. Plant Dis. 83:1174.

15. González, E., and Sutton, T. B. 2004. Population diversity within isolates of Colletotrichum spp. causing Glomerella leaf spot and bitter rot of apples in three orchards in North Carolina. Plant Dis. 88:1335-1340.

16. Guerber, J. C., and Correll, J. C. 2001. Characterization of Glomerella acutata, the teleomorph of Colletotrichum acutatum. Mycologia 93:216229. 
17. Guerber, J. C., Liu, B., Johnston, P., and Correll, J. C. 2003. Characterization of diversity in Colletotrichum acutatum sensu lato by sequence analysis of two introns, mtDNA and intron RFLPs, and mating compatibility. Mycologia 95:872-895.

18. Gunnell, P. S., and Gubler, W. D. 1992. Taxonomy and morphology of Colletotrichum species pathogenic to strawberry. Mycologia 84:157-165.

19. Johnston, P. R., and Jones, D. 1997. Relationship among Colletotrichum isolates from fruit-rots assessed using rDNA sequences. Mycologia 89:420-430.

20. Lardner, R., Johnston, P. R., Plummer, K. M., and Pearson, M. N. 1999. Morphological and molecular analysis of Colletotrichum acutatum sensu lato. Mycol. Res. 103:275-285.

21. Leite, R. P., Tsuneta, M., and Kishino, A. Y. 1988. Ocorréncia de mancha foliar de Glomerella em maicieira no estado do Paraná. Fundação Institito Agronômico do Paraná. Informe de Pesquisa, 81.

22. Nitzan, N., Hazanovsky, M., Tal, M., and Tsror (Lahkim), L. 2002. Vegetative compatibility groups in Colletotrichum coccodes, the causal agent of black dot of potato. Phytopathology 92:827-832.

23. Puhalla, J. E. 1985. Classification of strains of Fusarium oxysporum on the basis of vegetative compatibility. Can. J. Bot. 63:179-183.

24. Shi, Y., Correll, J. C., and Guerber, J. C. 1996. Frequency of Colletotrichum species causing bitter rot of apples in the southeastern United States. Plant Dis. 80:692-696.
25. Struble, F. B., and Keitt, G. W. 1950. Variability and inheritance in Glomerella cingulata (Stonem.) S. and V. S. from apple. Am. J. Bot. 37:563-576.

26. Sutton, T. B. 1990. Bitter rot. Pages 15-16 in: Compendium of Apple and Pear Diseases. A. L. Jones and H. S. Aldwinckle, eds. The American Phytopathological Society, St. Paul, MN.

27. Sutton, T. B., and Sanhueza, R. M. 1998. Necrotic leaf blotch of Golden Delicious-Glomerella leaf spot: A resolution of common names. Plant Dis. 82:267-268.

28. Talhinhas, P., Sreenivasaprasad, S., Neves-Martins, J., and Oliveira, H. 2002. Genetic and morphological characterization of Colletot-richum acutatum causing anthracnose of lupins. Phytopathology 2002:986996.

29. Taylor, J. 1971. A necrotic leaf blotch and fruit rot of apple caused by strain of Glomerella cingulata. Phytopathology 61:221-224.

30. Ureña-Padilla, A. R., MacKenzie, S. J., Bowen, B. W., and Legard, D. E. 2002. Etiology and populations genetics of Colletotrichum spp. causing crown and fruit rot of strawberry. Phytopathology 92:1245-1252.

31. Wasilwa, L. A., Correll, J. C., Morelock, T. E., and McNew, R. E. 1993. Reexamination of races of cucurbit anthracnose pathogen Colletotrichum orbiculare. Phytopathology 83:1190-1198.

32. Wheeler, H. E., and McGahen, J. W. 1952. Genetics of Glomerella X. Genes affecting sexual reproduction. Am. J. Bot. 39:110-119. 